\title{
Eupatilin attenuates diabetic nephropathy by upregulating matrix metalloproteinase-9 expression in diabetic rat kidney
}

\author{
Linxin $\mathrm{Xu}^{1}$, Guoliang $\mathrm{Shi}^{2}$, Yali $\mathrm{Xu}^{2}$, Gang Lin ${ }^{2}$, Wuzhou Zhang ${ }^{2}$, Jing Yang ${ }^{1 *}$ \\ 1Department of Endocrinology, The First Hospital of Shanxi Medical University, Taiyuan 030001, ${ }^{2}$ Department of \\ Endocrinology, Changzhi High-tech Development Zone Central Hospital, Shanxi 046000, China
}

*For correspondence: Email: jingyang6@hotmail.com; Tel/Fax: 0086-13603512746

\begin{abstract}
Purpose: To evaluate the nephro-protective effect of eupatilin in diabetic nephropathic (DN) rats. Method: Diabetes was induced by intraperitoneal administration of streptozotocin (STZ, $55 \mathrm{mg} / \mathrm{kg}$ ) and confirmed by fasting blood glucose results, while $D N$ was determined by measuring serum urea and creatinine levels on day 40 after STZ administration. The eupatilin-treated group received eupatilin at 50 and $100 \mathrm{mg} / \mathrm{kg}$, p.o. for 20 days, after which blood levels of some biochemical parameters, glomerulosclerosis index, eosinophilic cast index, and expression of MMP-9 were determined using standard procedures.

Results: Treatment with eupatilin significantly decreased serum levels of glucose, creatinine and urea, and increased creatinine clearance, compared to the negative control group. Moreover, eupatilin attenuated changes in kidney histopathology, and significantly enhanced the expression of MMP-9 in the kidney tissues of the $D N$ rats, relative to negative control group.

Conclusion: These results indicate that eupatilin attenuates renal failure in STZ-induced DN rats by upregulating the expression of MMP-9.
\end{abstract}

Keywords: Eupatilin, Streptozotocin, Diabetic nephropathy, MMP-9

\begin{abstract}
This is an Open Access article that uses a funding model which does not charge readers or their institutions for access and distributed under the terms of the Creative Commons Attribution License (http://creativecommons.org/licenses/by/4.0) and the Budapest Open Access Initiative (http://www.budapestopenaccessinitiative.org/read), which permit unrestricted use, distribution, and
\end{abstract} reproduction in any medium, provided the original work is properly credited.

Tropical Journal of Pharmaceutical Research is indexed by Science Citation Index (SciSearch), Scopus, International Pharmaceutical Abstract, Chemical Abstracts, Embase, Index Copernicus, EBSCO, African Index Medicus, JournalSeek, Journal Citation Reports/Science Edition, Directory of Open Access Journals (DOAJ), African Journal Online, Bioline International, Open-J-Gate and Pharmacy Abstracts

\section{INTRODUCTION}

Diabetic nephropathy (DN) is a chronic complication of diabetes and a leading cause of death worldwide. Reports in the literature reveal that $60 \%$ of diabetic patients usually suffer from DN. Several pathways contribute to the development of DN, such as hexosamine pathway and polyol pathway [2,3]. Uncontrolled blood glucose level enhances the production of advanced glycation end-products (AGEs) and stimulates protein kinase C (PKC) [4]. These result in the enhancement of expressions of connective tissue growth factor (CTGF), transforming growth factor (TGF)- $\beta$ and vascular endothelial growth factor (VEGF) [5]. These factors contribute to deleterious changes in renal physiology such as thickening of basement membrane, albuminuria, enhanced permeability to macromolecules, and glomerular hypertrophy. 
Extracellular matrix is degraded by matrix metalloproteinases (MMPs) [6]. Matrix metallopeptidase-2 (MMP-2) and MMP-9 play important roles in the development of DN [7]. It has been reported that MMP-9 induces oxidative stress and expressions of inflammatory cytokines which contribute to the development of DN [8].

The management of DN is complex. Currently, scientists are focusing on novel molecules that can target the different pathways involved in the pathogenesis of DN. Herbal drugs have been used as alternative medicine for treatment of chronic disorders, and most herbs used clinically have multi-target actions [9]. Eupatilin is a flavonoid isolated from Artemisia princeps Pampanini (Asteraceae) [10]. It possesses strong antioxidant and antiinflammatory properties [11,12]. Moreover, it has been reported that eupatilin exerts gastroprotective effects by attenuating gastric mucosal injuries [13]. The present study was aimed at evaluating the nephron-protective activity of eupatilin in STZ-induced DN rat model.

\section{EXPERIMENTAL}

\section{Animals}

Male albino Wistar rats weighing $120-150 \mathrm{~g}$ were procured from Shangai Animal House, China, and maintained under the standard conditions as per the Animal House guidelines. The rats were acclimatized to laboratory conditions for 7 days, and allowed free access to normal standard rat chow and tap water. The protocol for this study was approved by institutional animal ethical committee of the First Hospital of Shanxi Medical University, China (approval number $=$ IAEC/HSMU/2017/04). The study followed the guidelines of Association for the Assessment and Accreditation of Laboratory Animal Care International (AAALAC) for animal use and experimentation [14].

\section{Induction of diabetic nephropathy}

Streptozotocin (STZ) was administered intraperitoneally to overnight-fasted rats at a dose of $55 \mathrm{mg} / \mathrm{kg}$, while saline was given to control group animals. After $72 \mathrm{~h}$, fasting blood glucose was estimated using GOD-POD method. Rats with blood glucose levels higher than 200 $\mathrm{mg} / \mathrm{dL}$ were considered diabetic. After 40 days, DN was confirmed through proteinuria test. The rats were divided into four groups: control group without STZ, negative control, and two eupatilin groups given either 50 or $100 \mathrm{mg} / \mathrm{kg}$ eupatilinn p.o. All treatments lasted for 20 days, after which biochemical analyses were done in blood and urine of the $\mathrm{DN}$ rats.

\section{Determination of biochemical parameters}

Colorimetric methods were used for the estimation blood glucose, creatinine and urea on day 40 and day 60 using assay kits as per the instructions of kit manufacturers. Creatinine clearance was calculated using Eq 1.

Creatinine clearance $=$ (urinary $\mathrm{Cr} /$ serum Cr) urine volume ......................... (1)

Kidney index (K) was evaluated as in Eq 2.

$K=($ kidney weight/body weight) $100 \ldots . .$. (2)

\section{Histopathological examination of kidney tissue}

Kidney sections were dehydrated in increasing concentrations of ethanol, and kept in liquid paraffin. Tissue slices of $5 \mu \mathrm{m}$ thickness were cut in a microtome and stained using periodic acidSchiff (PAS) and hematoxylin-eosin ( $H$ \& E) stain. Histopathological changes in the kidney slices were observed under a Trinocular microscope.

\section{Evaluation of EC and glomerulosclerotic index}

Glomerulosclerotic index was used for the estimation of degree of glomerular damage. Tissue sections subjected to PAS staining were observed at $400 \times$ magnification, and semiquantitative method was used for scoring glomerular damage. The EC index was estimated by $\mathrm{H} \& \mathrm{E}$ staining of kidney tissues at 400x magnification, and was calculated as ratio of the number of tubules with EC to the total number of tubules.

\section{Assessment of MMP-9 expression}

Total RNA was extracted from kidney tissue with TRIzol reagent. Random hexamers were used to reverse-transcribe the total RNA (5 $\mu \mathrm{g})$ using superscript II RNase H-reverse transcriptase. Amplification was performed using $0.1 \mu \mathrm{mol} / \mathrm{L}$ of each primer for GAPDH, $0.4 \mu \mathrm{mol} / \mathrm{L}$ of primer for MMP9, $1.5 \mathrm{mmol} / \mathrm{L} \mathrm{MgCl} 2,200 \mu \mathrm{mol} / \mathrm{L}$ dNTPs, 5 $\mu \mathrm{L}$ cDNA, and $2.5 \mathrm{U}$ of Taq DNA polymerase. Denaturation of PCR sequence was initially achieved at $94{ }^{\circ} \mathrm{C}$ for $3 \mathrm{~min}$ and thereafter at 94 ${ }^{\circ} \mathrm{C}$ for $30 \mathrm{~s}, 58{ }^{\circ} \mathrm{C}$ for $30 \mathrm{~s}, 72{ }^{\circ} \mathrm{C}$ for $45 \mathrm{~s}$ for 35 cycles, and a final extension at $75^{\circ} \mathrm{C}$ for $5 \mathrm{~min}$. Electrophoresis was used for the separation of the amplified products, while Imagequant 
LAS500 was used to estimate the optical density of MMP-9.

\section{Statistical analysis}

Data are presented as mean \pm standard deviation (SD). One-way analysis of variance (ANOVA) and Dunnett's post-hoc test were used to analyse the data (Gradpad prism 6.1., CA, USA). Values of $p<0.05$ were considered significant.

\section{RESULTS}

\section{Effect of eupatilin on biochemical parameters}

The effect of eupatilin on blood glucose level and kidney function in STZ-induced DN rats was shown in Table 1 . There were significant $(p<$ 0.01 ) increases in the blood levels of glucose, creatinine and urea in the negative control group, when compared to the control group. Moreover, kidney index was significantly $(p<0.01)$ increased while creatinine clearance was decreased in the negative control, relative to control group. However, treatment with eupatilin significantly $(p<0.01)$ decreased serum concentrations of glucose, creatinine and urea, when compared with the control group. Kidney index was significantly decreased, while creatinine clearance was significantly increased in the eupatilin-treated groups, when compared to negative control group ( $p<0.05, p<0.01)$.

\section{Effect of eupatilin on kidney morphology}

Kidney tissue section from the control group showed normal structure of glomerulus surrounded by Bowman's capsule. However H \& $E$ staining of kidney sections from the negative control group showed dilatation and deposition of ECs in the proximal convoluted tubules, and cloudy swelling. PAS staining revealed signs of glomerular sclerosis in the negative control group, as evidenced by excessive deposition of ECM and thickening of glomerular basement which resulted in the destruction of the capillary lumen. However, treatment with eupatilin significantly reversed these histological changes in the kidney of DN rats. Moreover, eupatilin attenuated tubular necrosis due to DN. These results are shown in Figure 1 and Figure 2.

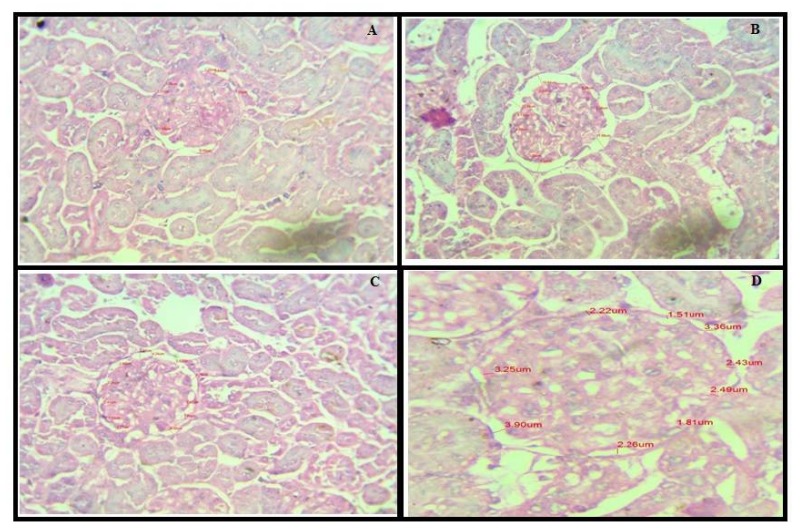

Figure 1: Effect of eupatilin on morphology of kidney tissue in STZ-induced DN rats ( $H$ \& $E$ staining). A: control group showing normal structure of glomerulus surrounded by Bowman's capsule; B: negative control group showing dilatation and deposition of ECs in the proximal convoluted tubules along with cloudy swelling; Attenuation of the DN-induced changes by $50 \mathrm{mg} / \mathrm{kg}$ eupatilin (C), and $100 \mathrm{mg} / \mathrm{kg}$ eupatilin (D)

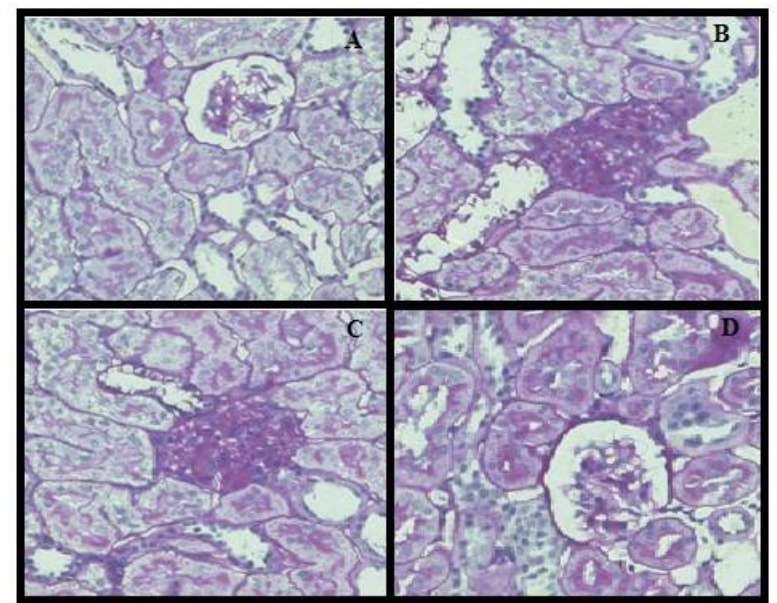

Figure 2: Effect of eupatilin on histology of kidney tissue of STZ-induced DN rats as determined by PAS staining for the estimation of glomerularsclerosis and deposition of ECM. A: control group; B: negative control group; C: eupatilin (50 mg/kg); D: eupatilin (100 mg/kg)

Table 1: Effect of eupatilin on blood glucose level and kidney function in STZ-induced DN rats

\begin{tabular}{lccccc}
\hline Group & $\begin{array}{c}\text { Blood glucose } \\
(\mathbf{m g} / \mathbf{d L})\end{array}$ & $\begin{array}{c}\text { Serum creatinine } \\
(\mathbf{m g} / \mathbf{d L})\end{array}$ & $\begin{array}{c}\text { Serum Urea } \\
(\mathbf{m g} / \mathbf{d L})\end{array}$ & Ccr $(\mathbf{m l} / \mathbf{m i n} / \mathbf{k g})$ & Kidney index \\
\hline Control & $91.24 \pm 3.60$ & $0.38 \pm 0.02$ & $39.25 \pm 1.82$ & $1.29 \pm 0.03$ & $3.20 \pm 0.27$ \\
Negative control & $321.50 \pm 12.80^{\# \#}$ & $1.49 \pm 0.08^{\# \#}$ & $121.5 \pm 6.80^{\# \#}$ & $0.27 \pm 0.01^{\# \#}$ & $6.10 \pm 0.47^{\# \#}$ \\
Eupatilin $50 \mathrm{mg} / \mathrm{kg}$ & $179.20 \pm 8.60^{* *}$ & $8.32 \pm 0.04^{* *}$ & $69.32 \pm 3.18^{* *}$ & $0.83 \pm 0.02^{* *}$ & $5.40 \pm 0.32^{*}$ \\
Eupatilin $100 \mathrm{mg} / \mathrm{kg}$ & $131.80 \pm 5.90^{* *}$ & $0.61 \pm 0.03^{* *}$ & $52.91 \pm 2.73^{* *}$ & $1.06 \pm 0.03^{* *}$ & $4.30 \pm 0.29^{* *}$ \\
\hline
\end{tabular}

Values are expressed as mean \pm SD $(n=8),{ }^{\# \#} p<0.01$, compared to control group; ${ }^{\star \star} p<0.01$, compared to negative control group 


\section{Effect of eupatilin on GSI and ECI}

The effect of eupatilin on glomerularsclerosis index and eosinophilic cast index in the kidney tissue of STZ-induced DN rats are shown in Figure 3. There were significant $(p<0.01)$ increases in the glomerularsclerosis index and eosinophilic cast index in the negative control group, when compared to control group. However treatment with eupatilin significantly $(p$ $<0.01$ ) reversed these $\mathrm{DN}$-induced changes, when compared to negative control group.

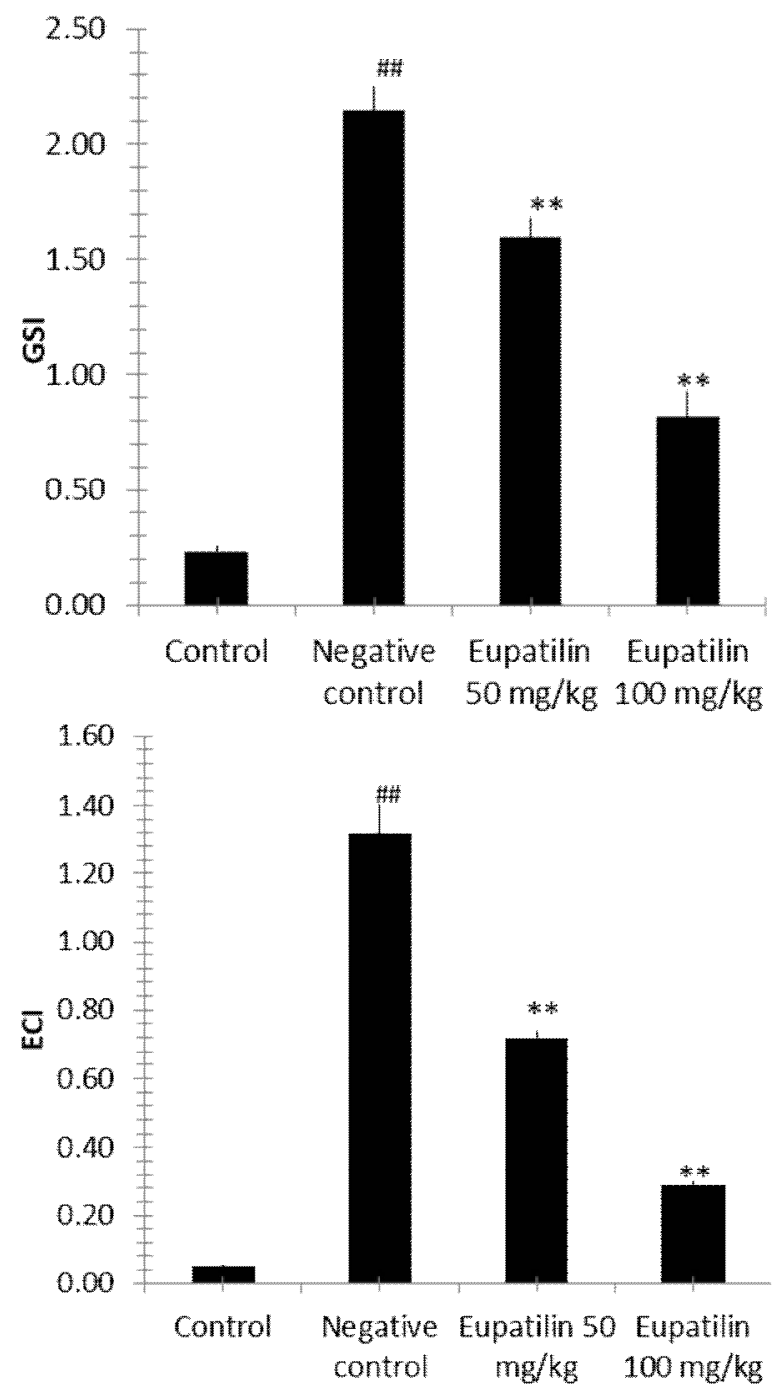

Figure 3: Effect of eupatilin on glomerularsclerosis index and eosinophilic cast index in the kidney tissue of STZ-induced DN rats. Values expressed as mean \pm $\mathrm{SD}(\mathrm{n}=8),{ }^{\# \#} p<0.01$ vs control group; ${ }^{* *} p<0.01$ vs negative control group

\section{Effect of eupatilin on the expressions of MMP-9}

The effect of eupatilin on the expression of MMP9 in the kidney tissue of STZ-induced DN rats is shown in Figure 4. It was observed that expression of MMP-9 in the kidney tissue of negative control group was significantly $(p<$ 0.01) decreased when compared to corresponding expression in the control group. In addition, the expression of MMP-9 was lower in kidney tissue of eupatilin-treated group than in kidney tissue of the negative control group.

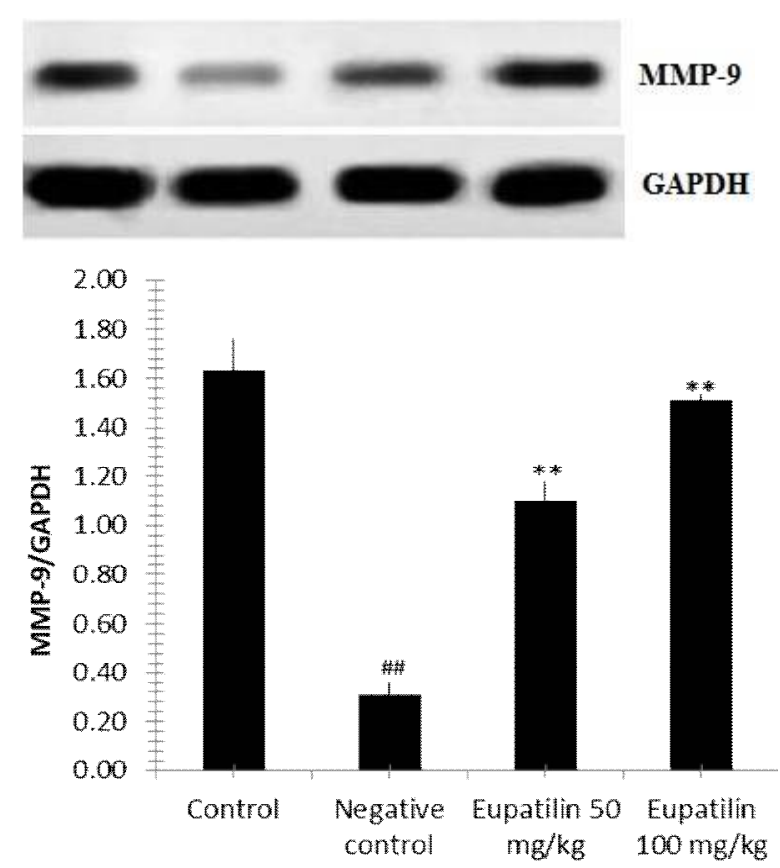

Figure 4: Effect of eupatilin on the expressions of MMP-9 in the kidney tissue of STZ-induced DN rats. Values are expressed as mean \pm SD $(n=8),{ }^{\#} p<0.01$, compared to control group; ${ }^{* *} p<0.01$, compared to negative control group

\section{DISCUSSION}

Diabetic nephropathy (DN) is one of the complications of diabetes which is characterized by increase in macroalbuminurea, thickening of basement membrane and glomerular hypertrophy [15]. The present study evaluated the nephroprotective effect of eupatilin in STZinduced DN rat model. The effect of eupatilin was assessed by estimating biochemical parameters in blood, and kidney function test in DN rats. However, histopathological studies and western blot assay were done for the estimation of MMP9.

Eupatilin exerts anti-hyperglycemic activity by enhancing the insulin secretion and hepatic metabolism of glucose. The results of this study have also indicated that treatment of DN rats with eupatilin significantly decreases blood glucose level. It has been reported that DN is characterized by increased serum levels of urea and creatinine, and decreases in creatinine clearance [16]. Urea and creatinine are metabolic wastes excreted via the urine. Thus, their levels 
are altered in DN. It is known that improvement in renal function also protects the nephrons [17]. This is in agreement with the attenuation of renal function in the DN rats by eupatilin, which also attenuated the alterations in the levels of biochemical parameters assayed.

The accumulation of ECM is one of the characteristics of DN-induced glomerularsclerosis. In addition, $\mathrm{GCl}$ and $\mathrm{ECl}$ are increased in DN [18]. It has been demonstrated that nephro-protective drugs attenuate histological changes, as well as $\mathrm{GCl}$ and $\mathrm{ECl}$ in kidney tissues of DN rats [19]. The results of the present study reveal that eupatilin attenuates histological changes in kidney tissues. Available literature indicate that the expression of MMP-9 is decreased in DN through the regulation of mesangial ECM turnover [20]. This is in agreement with the eupatilin-induced decrease in the expression of MMP-9 in the renal tissues of $\mathrm{DN}$ rats as demonstrated in the current study.

\section{CONCLUSION}

The findings of this study suggest that eupatilin enhances the expression of MMP-9 in the kidney tissues and thereby mitigates the renal injury in STZ-induced DN rat model. Thus, eupatilin has promising potential for use in the clinical management of DN.

\section{DECLARATIONS}

\section{Acknowledgement}

This study was supported financially by Wu Jieping Medical Foundation Project (no. 320.6750.15225) and Zhejiang Pharmaceutical Health Research Fund Project (no. 2017KY638).

\section{Conflict of interest}

No conflict of interest is associated with this work.

\section{Authors' contributions}

We declare that this work was done by the authors named in this article and all liabilities pertaining to claims relating to the content of this article will be borne by the authors. Jing Yang designed the study protocol, supervised the work and wrote the manuscript. Guoliang Shi, Yali Xu, Gang Lin and Wuzhou Zhang helped in the statistical analysis and histopathological studies. Linxin Xu performed the experimental work.

\section{REFERENCES}

1. The Diabetes Control and Complications Trial Research Group. The effect of intensive treatment of diabetes on the development and progression of long-term complications in insulin-dependent diabetes mellitus. $N$ Engl J Med. 1993; 329: 977-986.

2. Ojima $A$, Ishibashi $Y$, Matsui $T$, Maeda $S$, Nishino $Y$, Takeuchi M, Fukami K, Yamagishi S., Glucagon-like peptide-1 receptor agonist inhibits asymmetric dimethylarginine generation in the kidney of streptozotocin induced diabetic rats by blocking advanced glycation end product-induced protein arginine methyltranferase-1 expression. Am J Pathol. 2013; 182: 132-141.

3. Riedl E, Pfister F, Braunagel M, Brinkkötter $P$, Sternik $P$, Deinzer M, Bakker SJ, Henning $R H$, van den Born J, Krämer BK, Navis G, Hammes HP, Yard B, Koeppel H. Carnosine prevents apoptosis of glomerular cells and podocyte loss in STZ diabetic rats. Cellular physiology and biochemistry. 2011; 28: 279-288.

4. Juan $Y$-S, Chuang $S-M$, Long $C-Y$, Lin RJ, Liu KM, Wu $W J$, Huang $C H$. Protein kinase $C$ inhibitor prevents renal apoptotic and fibrotic changes in response to partial ureteric obstruction. BJU international. 2012; 110: 283292.

5. Sharma $V$, Sharma $P$. Role of different molecular pathways in the development of diabetes-induced nephropathy. Diabetes \& Metabolism. 2013; S9: 004.

6. Abrass CK. Diabetic nephropathy. Mechanisms of mesangial matrix expansion. The Western journal of medicine. 1995; 162: 318-321.

7. Catania JM, Chen G, Parrish AR. Role of matrix metalloproteinases in renal pathophysiologies. Am. J. Physiol. Renal Physiol. 2007; 292: F905-911.

8. McLennan SV, Kelly DJ, Cox AJ et al. Decreased matrix degradation in diabetic nephropathy: Effects of $A C E$ inhibition on the expression and activities of matrix metalloproteinases. Diabetologia. 2002; 45: 268-275.

9. Tripathi YB, Chaturvedi AP, Pandey N. Effect of Nigella sativa seeds extracts on iNOS through antioxidant potential only: crude/total extract as molecular therapy drug. Indian journal of experimental biology. 2012; 50: 413-418.

10. Choi EJ, Oh HM, Na BR, Ramesh TP, Lee HJ, Choi CS, Choi SC, Oh TY, Choi SJ, Chae JR, Kim SW, Jun CD. Eupatilin protects gastric epithelial cells from oxidative damage and down-regulates genes responsible for the cellular oxidative stress. Pharm Res 25: 1355-1364.

11. Ji HY, Kim SY, Kim DK, Jeong JH, Lee HS, Effects of eupatilin and jaceosidin on cytochrome p450 enzyme activities in human liver microsomes. Molecules 2010; 15: 6466-6475.

12. Lim JC, Park SY, Nam Y, Nguyen TT, Sohn UD. The Protective Effect of Eupatilin against Hydrogen Peroxide-Induced Injury Involving 5-Lipoxygenase in Feline Esophageal Epithelial Cells. Korean J Physiol Pharmacol 2012; 16: 313-320.

Trop J Pharm Res, June 2018; 17(6): 1059 
13. Cheong JH, Hong SY, Zheng $Y$, Noh SH, Eupatilin Inhibits Gastric Cancer Cell Growth by Blocking STAT3Mediated VEGF Expression. J Gastric Cancer 2011; 11: 16-22.

14. Guide for the Care and Use of Laboratory Animals: Eighth Edition Committee for the Update of the Guide for the Care and Use of Laboratory Animals; National Research Council. 2010; ISBN: 0-309-15401-4.

15. Tripathi AS, Mazumder PM, Chandewar AV. Evaluation of drug interaction of Glimepiride with Phosphodiesterase inhibitors Type 5 in Diabetic nephropathy. Exp Clin Endocrinol Diabetes 2014; 122(10): 597-601.

16. Tripathi AS, Chandewar AV, Mazumder PM. Change in the pharmacokinetic Sildenafil citrate in diabetic nephropathy. Journal of diabetes and metabolic disorders, 2014; 13(1):8.
17. Tripathi AS, Mazumder PM, Chandewar AV. Sildenafil, A Phosphodiesterase Type 5 Inhibitor, Attenuates Diabetic Nephropathy In STZ Induced Diabetic Rats. Journal of Basic physiology and pharmacology,2016; 27 (1): 57-62.

18. Hu C, Sun L, Xiao L, Han Y, Fu X, Xiong X, Xu X, Liu Y, Yang S, Liu F, Kanwar YS. Insights into the mechanisms involved in the expression and regulation of extracellular matrix proteins in diabetic nephropathy. Current medicinal chemistry. 2015; 22:2858-2870.

19. Srivastava S, Koley TK, Singh SK, Tripathi YB. The tuber extract of Pueraria tuberosa Linn. Competitively inhibits DPP-IV activity in normoglycemic rats. International Journal of Pharmacy and Pharmaceutical Sciences. 2015; 7: 277-301.

20. Suzuki D. Metalloproteinases in the pathogenesis of diabetic nephropathy. Nephron. 1998; 80: 125-33. 